\title{
Necrotizing enterocolitis: current perspectives
}

This article was published in the following Dove Press journal:

Research and Reports in Neonatology

17 March 2014

Number of times this article has been viewed

Phani Kiran Yajamanyam'

Shree Vishna Rasiah'

Andrew K Ewer ${ }^{1,2}$

'Neonatal Unit, Birmingham Women's Hospital NHS Foundation Trust,

${ }^{2} \mathrm{School}$ of Clinical and Experimental Medicine, University of Birmingham,

Birmingham, UK
Correspondence: Phani Kiran

Yajamanyam

Birmingham Women's Hospital NHS

Foundation Trust, Mindelsohn Way,

Birmingham, UK BI5 2TG

Tel +44 I2 I627 2689

Fax +44 I2 I627 2749

Email kiran.yajamanyam@bwhct.nhs.uk
Abstract: Necrotizing enterocolitis is the most common gastrointestinal emergency in neonates, particularly in those born very preterm. It is a leading cause of morbidity and mortality, especially in extremely low birth weight infants. Despite extensive research, the pathophysiology of necrotizing enterocolitis remains unclear and therapeutic options are limited. Multiple risk factors have been reported, but most are associated with prematurity and its complications. This makes management very challenging in vulnerable preterm infants. In this review, we focus on the risk factors and some of the current research in this area, particularly studies aimed at early detection and potential preventive measures for this potentially lethal condition.

Keywords: necrotizing enterocolitis, preterm infants, prematurity, probiotics

\section{Background}

Necrotizing enterocolitis (NEC) can be defined as an acute inflammatory disease occurring in the intestines of the newborn, particularly in preterm infants, and is characterized by hemorrhagic necrosis of intestinal tissue which may lead to perforation and destruction of the gut.

$\mathrm{NEC}$ is the most common neonatal gastrointestinal emergency, particularly in those born at $<32$ weeks' gestation and/or $<1,500 \mathrm{~g}$ birth weight. NEC remains a challenging condition for neonatologists worldwide, with unclear pathogenesis, treatment options that might prove inadequate, a mortality rate as high as $50 \%,{ }^{1}$ and high morbidity among survivors of significant disease, including short gut syndrome and significantly increased hospitalization. ${ }^{1}$ Even though it was first described more than a century ago, ${ }^{2}$ and although significant recent advances have been achieved in other complications of prematurity, such as respiratory distress syndrome, NEC remains a major cause of death. The main difficulties are predicting which babies will develop the disease and establishing the diagnosis before fulminant disease has occurred.

\section{Epidemiology}

Numerous epidemiological studies have attempted to describe the incidence and prevalence of NEC based on either gestational age at birth or birth weight. Table 1 shows the reported incidence in a number of developed countries for periods between 1994 and 2009. ${ }^{3-9}$ Although there are minor differences in both the infants investigated and the incidence of NEC, an increase in the incidence of NEC among infants born $<32$ weeks' gestation or $<1,500 \mathrm{~g}$ has been reported, ${ }^{9}$ which may be linked to the increasing survival of infants born extremely preterm. Variation in the incidence of NEC between centers 
Table I Epidemiological studies describing the incidence of necrotizing enterocolitis

\begin{tabular}{|c|c|c|c|c|}
\hline Country & Study period & Infants (n) & Infant categorization & Incidence of NEC \\
\hline \multirow[t]{3}{*}{ Canada $^{5}$} & $1996-1997$ & 18,234 & Birth weight & \\
\hline & & & $<\mathrm{I}, 500 \mathrm{~g}, \mathrm{n}=3,628$ & $6.6 \%(<\mathrm{I}, 500 \mathrm{~g})$ \\
\hline & & & $>1,500 \mathrm{~g}, \mathrm{n}=14,606$ & $0.7 \%(>1,500 \mathrm{~g})$ \\
\hline New South Wales, & $1994-1999$ & 4,649 & Gestation & \\
\hline Australia $^{6}$ & & & 24-3I weeks, $n=4,649$ & $3.8 \%$ \\
\hline NICHD Neonatal & $|998-200|$ & 11,936 & Birth weight & \\
\hline Network, USA ${ }^{7}$ & & & $<\mathrm{I}, 500 \mathrm{~g}, \mathrm{n}=1 \mathrm{I}, 936$ & $7.1 \%$ \\
\hline \multirow[t]{6}{*}{$\mathrm{UK}^{8}$} & $2005-2006$ & 10,946 & Total $n=10,946$ & $2 \%$ \\
\hline & & (total NICU & Birth weight & \\
\hline & & admissions) & I,000 g, n=87| & $14.4 \%$ \\
\hline & & & Gestation & \\
\hline & & & $<26$ weeks, $n=386$ & $13.8 \%$ \\
\hline & & & $26-28$ weeks, $n=656$ & $10.8 \%$ \\
\hline \multirow[t]{2}{*}{ Sweden 9} & 2004-2007 & 497 & Gestation & \\
\hline & & & $<27$ weeks, $n=497$ & $5.8 \%$ \\
\hline Canada $^{10}$ & $2003-2008$ & 16,669 & $<33$ weeks & $5.1 \%$ \\
\hline \multirow[t]{7}{*}{ Sweden" } & $1987-2009$ & $2,381,318$ & Gestation & \\
\hline & & & $<28$ weeks, $n=6,595$ & $4.6 \%$ \\
\hline & & & 28-31 weeks, $n=\mid 4,822$ & $1.4 \%$ \\
\hline & & & Birth weight & \\
\hline & & & $<750 \mathrm{~g}, \mathrm{n}=2,768$ & $5.3 \%$ \\
\hline & & & $750-999 \mathrm{~g}, \mathrm{n}=3,793$ & $4.1 \%$ \\
\hline & & & $\mathrm{I}, 000-1,499 \mathrm{~g}, \mathrm{n}=\mathrm{I} \mathrm{I}, 047$ & $1.5 \%$ \\
\hline
\end{tabular}

Abbreviations: NEC, necrotizing enterocolitis; NICHD, National Institute of Child Health and Development; NICU, neonatal intensive care unit.

is well reported, and potential explanations include inherent population variability, differences in the local prevalence of microorganisms, and possible minor epidemics. ${ }^{10}$

\section{Pathogenesis}

NEC is characterized by a significant proinflammatory response involving a host of inflammatory mediators, including platelet-activating factor, interleukins (such as IL-1 and IL-6), and tumor necrosis factor- $\alpha .{ }^{11}$ The mechanisms leading to clinically apparent NEC are unclear, although various causal factors have been proposed (Figure 1). The most well recognized causal factors are prematurity, hypoxia-ischemia, bacterial colonization, and enteral feeding.

\section{Prematurity}

The vast majority of NEC occurs in infants born preterm, ${ }^{12,13}$ although up to $10 \%$ of all cases affect late preterm and term babies. ${ }^{14}$ The preterm gastrointestinal tract is potentially more susceptible to NEC as a result of immature barrier function of the intestinal mucosa, ${ }^{15}$ inadequate digestion of feeds, ${ }^{16}$ immature intestinal circulatory regulation, ${ }^{17}$ and immature innate immunity.

\section{Hypoxia-ischemia}

Hypoxia-ischemia as a primary causative factor in the pathogenesis of $\mathrm{NEC}^{18}$ has not been proven in clinical studies. ${ }^{19}$
However, in those full-term or near-term infants with comorbidities such as congenital heart disease (which may predispose to impaired systemic circulation), hypoxicischemic injury appears to have a much greater role in the pathogenesis of NEC. ${ }^{20}$

\section{Bacterial colonization}

It is now recognized that abnormal microbial colonization of the preterm gut has a definitive role to play in the pathogenesis of NEC. ${ }^{21,22}$ Although no single organism has been identified as a causative agent for NEC, the well reported evidence of epidemics or clusters of NEC also strongly suggests the role of microorganisms in the origin of the disease. ${ }^{23}$

\section{Enteral feeding}

NEC predominantly occurs in babies who have been enterally fed, ${ }^{24}$ although it has occasionally been reported in completely unfed babies. ${ }^{25,26}$ Feeding with formula milk appears to increase the risk of NEC, whereas breast milk has a protective effect. ${ }^{27,28}$ The timing of initiation and speed of increase of enteral feeds is a subject of much debate. Sisk et $\mathrm{al}^{29}$ have reported a significant decrease in the risk of NEC with early breast milk feeding in preterm infants, while a recent Cochrane systematic review concluded that delaying the introduction of enteral feeds for up to 5-7 days did not increase the risk of developing NEC in very preterm infants. ${ }^{30}$ 


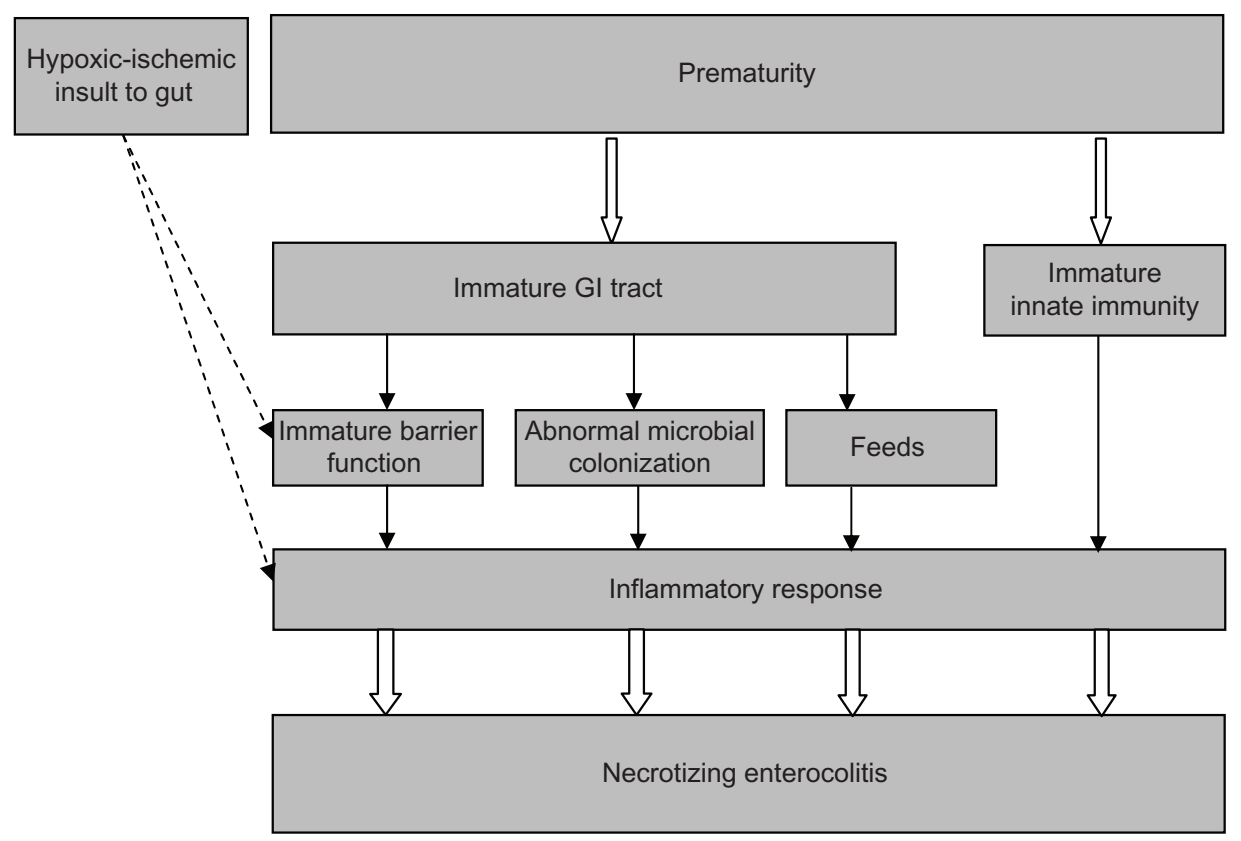

Figure I Pathogenesis of NEC.

Abbreviations: $\mathrm{Gl}$, gastrointestinal; NEC, necrotizing enterocolitis.

\section{Classification}

NEC was classified according to disease severity by Bell in 1978 (Table 2) ${ }^{31}$ A more recent classification was proposed by Gordon et al, ${ }^{32}$ encompassing other acquired neonatal gastrointestinal disorders in the preterm infant that might mimic NEC, such as feeding intolerance of prematurity, viral enteritis of infancy, spontaneous intestinal perforation, NEC caused predominantly by ischemia, and cow's milk protein allergy.

There have been several recent reviews on this topic. . $^{1,212,33}$ This review will focus mainly on the potential risk factors associated with NEC and some of the current research relating to prevention and early diagnosis of NEC.

\section{Risk factors associated with NEC Prematurity and low birth weight}

The biggest single risk factor for NEC is prematurity, ${ }^{3-9}$ with more than $85 \%$ cases of NEC occurring in either very preterm infants ( $<32$ weeks) or in very low birth weight infants $(<1,500 \mathrm{~g})$, and only around $10 \%$ of all cases of NEC are reported in either late preterm or term infants. ${ }^{14,34}$ Evidence is emerging that the age of onset of NEC is inversely proportional to the gestational age at birth, ie, the more immature the infant, the later the onset of NEC. . $^{34,35}$

The barrier function of the preterm gastrointestinal tract is immature, both in its structure and secretory activity. ${ }^{36-40}$ Mucosal permeability of the preterm gut is higher compared

Table 2 Modified Bell's staging system

\begin{tabular}{lll}
\hline Stage & Gastrointestinal signs & Systemic signs \\
\hline $\begin{array}{l}\text { Stage IA } \\
\text { Suspected NEC }\end{array}$ & $\begin{array}{l}\text { Increasing gastric aspirates, mild abdominal } \\
\text { distension, fecal occult blood }\end{array}$ & $\begin{array}{l}\text { Temperature instability, } \\
\text { apnea, bradycardia, lethargy } \\
\text { Stage IB }\end{array}$ \\
$\begin{array}{l}\text { As above plus fresh blood per-rectum } \\
\text { Stage IIA }\end{array}$ & As above \\
$\begin{array}{l}\text { Confirmed NEC } \\
\text { Stage IIB }\end{array}$ & $\begin{array}{l}\text { As above plus absent bowel sounds } \\
\text { on auscultation }\end{array}$ & As above \\
$\begin{array}{l}\text { Confirmed NEC } \\
\text { Stage IIIA }\end{array}$ & $\begin{array}{l}\text { As above plus abdominal tenderness } \pm \\
\text { abdominal mass }\end{array}$ & As above plus mild metabolic \\
Advanced NEC & As above plus marked distension and & acidosis and thrombocytopenia \\
Stage IIIB & tenderness + generalised peritonitis & As above plus hypotension \\
Advanced NEC & As above & and severe apnea
\end{tabular}

Notes: Adapted with permission from Walsh MC, Kliegman RM. Necrotizing enterocolitis: treatment based on staging criteria. Pediatr Clin North Am. I986;33(I): 179-20 I. ${ }^{131}$ (C) 1986 Elsevier.

Abbreviation: NEC, necrotizing enterocolitis. 
with that in term infants, and this could potentially play a role in the pathogenesis of NEC. ${ }^{36}$ The mucin layer lining the intestinal mucosa in the preterm gut is thinner than in term infants, and this may lead to increased bacterial adherence and increased mucosal permeability, both of which predispose to mucosal injury and development of NEC. ${ }^{37}$ In preterm infants affected by NEC, mucosal injury has been shown to lead to increased nitric oxide production which, in turn, accentuates epithelial injury, thus increasing the susceptibility to NEC. ${ }^{38}$ The preterm gut affected by NEC has also been shown to have fewer and immature Paneth cells ${ }^{15,39}$ (specialized crypt cells in the human intestine producing natural antimicrobials, such as lysozyme) with near absence of lysozyme. ${ }^{40}$

The immature nature of the preterm immune system is thought to play a major role in the development of NEC. ${ }^{41-44}$ Various toll-like receptors have been identified in the human intestinal epithelial cells which assist in strengthening the intestinal barrier function by identifying pathogens in the intestinal lumen. ${ }^{41}$ Changes in the expression of tolllike receptors (particularly TLR4 and TLR9) have been found to precede the development of NEC in a rat model. ${ }^{41}$ In experimental studies, suppression of inflammatory mediators such as platelet-activating factor and tumor necrosis factor- $\alpha$ resulted in a less severe disease. ${ }^{42,43}$ It is still unclear whether preterm infants lack the ability to suppress the exaggerated inflammatory response (which may arise as a result of normal stimuli such as colonization with commensal bacteria or the introduction of enteral feeds) or if preterm infants are unable to mount an adequate inflammatory response to pathogenic bacteria. ${ }^{44}$

The microbiota of preterm infants is significantly less diverse, ${ }^{45,46}$ possibly as a result of prolonged use of antibiotics and the adverse nosocomial environment of the neonatal intensive care unit. Studies have compared the gut microbiome of preterm infants with clinical NEC with matched controls by investigating stool samples, and demonstrated an increase in particular species of bacteria (eg, proteobacteria) days before the onset of disease. ${ }^{45,47}$ This change in bacterial colonization of the gut in preterm infants further suggests the causative role of bacteria in the pathogenesis of NEC.

\section{Intrauterine growth restriction}

Preterm infants with poor fetal growth may be at a greater risk of developing NEC. ${ }^{48-50}$ In a large retrospective analysis, Garite et al reviewed the outcomes of almost 30,000 premature infants born before 34 weeks of gestation. ${ }^{48}$ Infants were categorized into three groups: small for gestational age (birth weight below the 10th centile); antenatally diagnosed intrauterine growth restriction (IUGR) and small for gestational age; and antenatally diagnosed IUGR but a birth weight above the 10th centile. These groups were compared with controls matched for gestational age. After correction for antenatal steroid exposure, gender, and mode of delivery, infants with a birth weight below the 10th centile and infants who were diagnosed as IUGR and had a birth weight below the 10th centile were more likely to die or develop severe intraventricular hemorrhage, severe retinopathy of prematurity, and NEC. Infants who were diagnosed antenatally as IUGR but had a birth weight above the 10th centile had similar outcomes as controls. Manogura et al reviewed 404 infants affected by growth restriction due to placental disease. ${ }^{49}$ Thirty-nine developed NEC, giving an incidence of $9.7 \%$ across all gestations; in addition, birth weight $<790 \mathrm{~g}$ remained a predominant risk factor for NEC. A recent meta-analysis investigating the outcomes of preterm infants affected by growth restriction compared with those without growth restriction found that the incidence of NEC was at least 2.5 times higher in preterm infants with growth restriction. ${ }^{50}$

However, some experimental studies in animals have not demonstrated an association between IUGR and NEC. Che et al compared the incidence of NEC in normal weight and IUGR preterm pigs ${ }^{51}$ divided into two broad groups, ie, one fed immediately and one where feeds were delayed for 2-3 days. The incidence of NEC was similar between the normal weight and IUGR preterm pigs, but was higher in those fed formula milk. The limitation of this study was that the preterm pigs were delivered at $91 \%-93 \%$ gestation, which may not be equivalent to the extreme preterm human neonates who are the most susceptible to NEC. Until further evidence from prospective studies is available for severe IUGR (below the 10th centile) preterm infants, this remains a potential risk factor for NEC.

\section{IUGR and abnormal antenatal Doppler ultrasound}

Doppler ultrasound examination of fetal blood vessels has become part of routine antenatal surveillance, particularly when pregnancies are complicated by fetal growth restriction. It is suggested that in such fetuses, blood flow to the brain is preserved at the expense of blood flow to other organs, including the gastrointestinal tract. ${ }^{52}$ Whether this antenatal reduction in blood flow to the gut poses an additional risk factor for the development of NEC has remained a significant concern among neonatologists. A meta-analysis 
of 14 observational studies examining fetuses with absent or reversed end diastolic flow in the umbilical arteries concluded that there is an increased risk of developing NEC among these infants, with an OR of 2.13 (95\% confidence interval [CI] 1.49-3.03). ${ }^{53}$ ADEPT (the Abnormal Doppler Enteral Prescription Trial) $)^{52}$ was a multicenter investigation conducted in the UK and Ireland to evaluate the effect of early introduction of enteral feeds in preterm infants born before 35 weeks' gestation with birth weight below the 10th centile and abnormal antenatal umbilical Doppler wave forms. Feeds were introduced either on day 2 or day 6 of life. There was no difference in the incidence of NEC between the two groups, and the early fed group achieved full enteral feeds much earlier, with less dependence on parenteral nutrition and a lower incidence of cholestatic jaundice. Although the evidence suggests that babies with IUGR and abnormal antenatal Dopplers are at increased risk of developing NEC, early initiation of breast milk feeds does not appear to increase the incidence of NEC in this population.

\section{Patent ductus arteriosus}

Patent ductus arteriosus (PDA) is diagnosed in approximately one third of babies born before 30 weeks' gestation and in more than $60 \%$ of babies born $<28$ weeks' gestation. $^{54}$ The presence of a large, hemodynamically significant PDA in preterm infants can lead to the "steal" phenomenon, compromising blood flow to organs distal to the PDA, including the gastrointestinal tract, potentially increasing the risk of developing NEC. Dollberg et al analyzed data from over 6,000 babies born between 24 and 34 weeks' gestation from the national database in Israel. ${ }^{55}$ The overall incidence of NEC in these babies was comparable with that in other studies (5.5\%), but in babies with PDA the incidence of NEC was significantly greater at $9.4 \%$ (OR 1.85). In a more recent study, Saldeno et al compared babies with a persistent PDA for $>3$ weeks with babies with a persistent PDA for $<3$ weeks. ${ }^{56}$ Twenty-nine percent of babies with PDA for $>3$ weeks developed NEC compared with only $5 \%$ of babies with a PDA that persisted for $<3$ weeks. Despite this, various trials that have targeted treatment of PDA have consistently failed to show any difference in the incidence of NEC. ${ }^{57,58}$ Because of the lack of conclusive evidence, further investigation, in the form of prospective randomized trials, is needed to establish a causative relationship between PDA and NEC. Until such evidence is available, we have to be aware that the presence of a hemodynamically significant PDA poses a potential risk for developing NEC.

\section{Enteral feeding}

In preterm infants, numerous short-term and long-term advantages of breast milk are well established. ${ }^{59}$ These include better feed tolerance, reduced infection rates, better neurodevelopmental outcomes, fewer hospital readmissions in childhood, and a reduction in incidence of NEC. In preterm babies, rightly so, no randomized controlled trials have been performed comparing maternal breast milk with formula and its effect on the incidence of NEC. ${ }^{60}$ However, in a prospective multicenter study, the incidence of NEC was 6-10 times higher in exclusively formula-fed infants when compared with exclusively breast milk-fed infants, and three times higher when compared with infants who received breast milk and formula. ${ }^{27}$ Donor milk was found to be as protective as maternal breast milk, and this risk persisted across all gestations. A Cochrane review analyzing the trials comparing donor breast milk versus formula feeds for preterm infants concluded that preterm babies who received formula milk were twice as likely to have NEC compared with preterm babies who received donor breast milk, thus highlighting the protective nature of donor breast milk. ${ }^{28}$ Studies have also looked at the minimum proportion of human milk that a preterm infant should receive to gain these benefits. Sisk et al found that, for every $25 \%$ increase in the proportion of human milk a preterm infant received, the odds of having NEC decreased by $38 \%{ }^{29}$ Therefore, the evidence strongly suggests that breast milk (maternal or donor) offers protection against NEC.

The optimum timing for initiation and advancement of enteral feeds in preterm infants remains an area where strong evidence is lacking, resulting in varying feeding practices among different neonatal units. ${ }^{61}$ Early initiation of enteral feeds in preterm infants with very small non-nutritive volumes (known as trophic feeding or minimal enteral nutrition) is thought to have several advantages over complete fasting as a result of "priming" the gastrointestinal tract and aiding in its maturation processes. ${ }^{62-64}$ Trophic feeds might achieve this by improving overall gut motility, ${ }^{62}$ secretion of certain digestive enzymes, ${ }^{63}$ and promoting colonization with commensal bacteria when maternal breast milk is used. ${ }^{64}$ Both animal and human studies have shown that starvation leads to mucosal atrophy, ${ }^{65}$ lack of stimulation of trophic hormones, ${ }^{66}$ increased intestinal translocation of bacteria, and sepsis. ${ }^{67}$ As a result, it is now common practice to commence enteral feeds at very small volumes, eg, 10-20 mL/ $\mathrm{kg} /$ day at intervals of 2-6 hours. However, a Cochrane systematic review of all studies comparing trophic feeds with complete fasting in preterm infants concluded that there was no difference in 
terms of incidence of NEC, feed tolerance, or growth rates. ${ }^{68}$ Because of the lack of harm and the likely physiological benefits mentioned previously, it is routine practice to commence enteral feeds in very low birth weight infants as early as possible, preferably with maternal breast milk.

Once trophic feeds have been started, the timing of increasing enteral feeds is still unclear. A Cochrane systematic review compared the commencement of increasing enteral feeds (either within 4 days or later than 5-7 days), ${ }^{30}$ and found no differences in the incidence of NEC (relative risk [RR] 0.92 , 95\% CI $0.64-1.34$ ) or all-cause mortality (RR 1.26, 95\% CI 0.78-2.01) between these two groups. An additional concern is the rate of increase of enteral feeds in the most vulnerable preterm infants. A Cochrane review, which included nearly 600 infants, compared two feeding regimens (increasing feeds at $15-20 \mathrm{~mL} / \mathrm{kg} /$ day or $30-35 \mathrm{~mL} / \mathrm{kg} /$ day) and found no significant difference in the risk of NEC (RR $0.91,95 \%$ CI $0.47-1.75$ ) or mortality (RR 1.43, 95\% CI 0.78-2.61). ${ }^{69}$ Currently, a large multicenter trial in the UK has just started recruiting patients to evaluate the effect of two speeds of daily increments of milk feeds (30 mL/kg/day versus $18 \mathrm{~mL} / \mathrm{kg} /$ day) in very preterm and very low birth weight infants. ${ }^{70}$

There is evidence that use of standardized feeding regimens leads to decreased rates of NEC. ${ }^{71}$ A total of six observational studies were reviewed in a meta-analysis. These studies were conducted between 1978 and 2003, and feeding practices varied widely between the studies. The implementation of a standardized feeding protocol within a neonatal unit significantly decreased the incidence of NEC in all the studies (pooled risk ratio $0.13,95 \%$ CI $0.03-0.5$; or a reduction of NEC incidence by $87 \%$ ), irrespective of the finer details of the protocol. This difference was independent of the use of trophic feeds or the use of exclusive breast milk. Whilst we await the results of the above UK trial, it would seem prudent that every neonatal unit should implement a standardized feeding regimen for babies at risk of NEC.

Given that maternal or donor breast milk often does not meet the nutrient requirements of preterm babies, supplementing breast milk with fortifier to provide additional protein, calcium, and phosphorus has been shown to improve weight gain, and linear and head growth. ${ }^{72,73}$ However, there are concerns that addition of fortifiers to human milk increases the risk of NEC. A Cochrane review evaluating the benefit of fortification of human breast milk showed no statistically significant increase in NEC in infants receiving fortified human milk (RR 1.33, 95\% CI 0.7-2.5). ${ }^{74}$ Sullivan et al studied the effect of human milk-based fortifier compared with bovine milk-based fortifier on neonatal morbidity among preterm infants. ${ }^{75}$ The incidence of NEC was significantly lower in babies receiving human milk-based fortifier compared with those who received bovine milk-based fortifier $(P=0.02)$, and the incidence of NEC requiring surgery was also significantly lower in the human milk-based fortifier group $(P=0.007)$. Despite this, it is now common practice to fortify breast milk with cow's milk-based fortifiers (because human milk-based fortifiers are not yet widely available in all countries) once preterm babies have established full enteral feeds.

\section{Blood transfusion}

The observation of NEC occurring within 36-72 hours after blood transfusion is increasingly common. In a meta-analysis of 11 retrospective case-control studies and one cohort study, Mohamed and Shah reported the association between blood transfusion and NEC. ${ }^{76}$ The total number of transfusionassociated NEC cases in the meta-analysis was 365 . The OR of NEC being present after a recent blood transfusion was 2.01, indicating a significant association. However, the PINT (Premature Infants in Need of Transfusion) study, which compared low and high hemoglobin thresholds for blood transfusion in preterm infants, found no difference in the rates of NEC $(8.5 \%$ in the low threshold arm versus $5.3 \%$ in the high threshold arm, $P=0.2) .{ }^{77}$ There is some suggestion that withholding feeds during blood transfusion may decrease the risk of developing transfusion associated $\mathrm{NEC} ;{ }^{78}$ however, the evidence for this is not substantiated by prospective trials. The description of transfusion-associated $\mathrm{NEC}^{79}$ and/or transfusion-related acute gut injury ${ }^{80}$ are often used synonymously and have emerged only in the last few years, and because this is based mainly on evidence from retrospective studies, further prospective investigation is required to establish causation.

\section{Medications}

Prolonged use of initial empirical antibiotics in preterm infants has been shown to be associated with an increased incidence of NEC and late-onset sepsis. ${ }^{81,82}$ Alteration of the intestinal microbiota is hypothesized as the possible mechanism. Guillet et al studied the association between use of $\mathrm{H} 2$ blockers and incidence of NEC5 in a large cohort of very low birth weight infants $(n=11,072)$. Antecedent H2 blocker use was associated with an increased incidence of NEC $(P<0.0001)$. The potential effect of increasing gastric $\mathrm{pH}$ on the colonization of intestinal bacteria may explain this observation. 
The vasoconstrictive effects of cyclooxygenase inhibitors like indomethacin and ibuprofen increase concerns about reducing gastrointestinal blood flow and therefore increasing the risk of NEC. ${ }^{83}$ Treatment of PDA with indomethacin is not associated with an increase in the incidence of NEC, ${ }^{57}$ although a Cochrane review comparing ibuprofen and indomethacin for the treatment of PDA concluded that ibuprofen use was associated with less NEC than indomethacin. ${ }^{58}$

\section{Umbilical arterial catheters}

There have been concerns that the position of umbilical arterial catheters may affect gastrointestinal blood flow by compromising the blood flow within the aorta.$^{84}$ However, a Cochrane systematic review analyzed six trials (of which five were randomized controlled trials) evaluating the evidence supporting a high or low position. ${ }^{85}$ In a total of 1,569 infants included in the meta-analysis, there was no difference in the incidence of NEC between the two groups (risk ratio 1.34, 95\% CI 0.79-2.25).

\section{Chorioamnionitis}

Given that the role of inflammation in the pathogenesis of NEC is increasingly recognized, it has been suggested that antenatal inflammatory processes like chorioamnionitis may increase the susceptibility of preterm infants to develop NEC.$^{86}$ Numerous recent studies have investigated the association between chorioamnionitis and NEC. ${ }^{87-91} \mathrm{~A}$ recent systematic review by Been et al analyzed 33 studies examining the association between chorioamnionitis and NEC. ${ }^{92}$ Three distinct groups were identified, ie, clinical chorioamnionitis, histological chorioamnionitis, and histological chorioamnionitis with fetal involvement. Clinical chorioamnionitis and histological chorioamnionitis with fetal involvement were associated with an increased incidence of NEC (OR 1.24, 95\% CI 1.01-1.52 and OR 3.29 (95\% CI 1.87-5.78, respectively), whereas histological chorioamnionitis alone did not result in a statistically significant association (OR 1.39, 95\% CI 0.95-2.04). The authors concluded that the meta-analysis provides evidence of an association between chorioamnionitis and NEC. However the authors also refer to the presence of potential confounders, such as the higher incidence of chorioamnionitis at lower gestation ages (which may partly explain the higher incidence of NEC in the chorioamnionitis group, with gestation acting as a major confounder) and a lower rate of breast feeding in the chorioamnionitisaffected mothers. Decreased intestinal mucosal thickness and increased mucosal permeability as a result of inflammatory mediators may explain this association. ${ }^{93}$

\section{Management}

Treatment of NEC follows a stepwise approach depending on disease severity. Initial medical management (conservative treatment) involves immediate cessation of feeds and aspiration of gastric contents, regular aspiration, gastric decompression via a nasogastric tube, and broad spectrum antibiotics. The antibiotics used usually depend on local policy (which may be dependent on the local flora), but should cover all potential pathogens including anaerobes. Anaerobic cover is particularly important if there is suspicion of perforation or in severe disease with systemic signs. ${ }^{12,14}$ Confirmation of the diagnosis of NEC is limited to abnormal radiographs and histopathology, both of which indicate established disease.

Up to $40 \%$ of cases of NEC require surgical intervention, ${ }^{1,12}$ but the decision of when to intervene surgically in NEC remains unclear. Recognized indications for surgery include: pneumoperitoneum due to intestinal perforation; evidence of necrotic bowel; palpable abdominal mass; development of intestinal stricture; and when there is no improvement or deterioration (including persistent hematological and biochemical derangements such as progressive thrombocytopenia and worsening metabolic acidosis) despite maximal conservative therapy. ${ }^{94,95}$ Increasing abdominal distension causing difficulty in ventilation may also prompt surgical intervention, including peritoneal drainage (see below). A scoring system comprising metabolic acidosis, hypotension, thrombocytopenia, hyponatremia, positive blood culture, neutropenia, and left shift of neutrophils has been suggested as an adjunct to the clinical and radiological parameters to aid in the timing of surgical intervention, ${ }^{96}$ but application of this system is not widely practiced.

Primary peritoneal drainage can be used as an alternative to laparotomy in unstable preterm infants with NEC. Various investigators have explored the benefits of primary peritoneal drainage over laparotomy. A recent Cochrane review on this topic concluded that there was no difference in mortality, hospital stay, or dependence on total parenteral nutrition. ${ }^{97}$ However, there is some suggestion that infants who undergo laparotomy instead of primary peritoneal drainage have a better neurodevelopmental outcome at 18 months of age. ${ }^{98}$ A multicenter trial in the US is currently recruiting patients to compare the effectiveness of laparotomy versus primary peritoneal drainage in NEC. ${ }^{99}$ Based on current evidence, the surgical management of NEC remains at the discretion of the local surgical team.

\section{Mortality}

Mortality among infants affected by NEC varies with disease severity and therefore the need for surgery. 
Reported mortality ranges from $20 \%$ to $50 \%$ and the risk of death increases with decreasing birth weight and gestation. ${ }^{1}$ The rates of surgical intervention vary widely among studies from $20 \%$ to $60 \%$, and the mortality rates among infants needing surgery for NEC can be as high as $50 \% .{ }^{100}$ There is concern that the mortality rates among infants affected by NEC may be increasing. Rees et $\mathrm{al}^{101}$ analyzed the national population registries for births and deaths in England and Wales between 1999 and 2005. They reported that although both total infant mortality and mortality among extremely low birth weight infants $(<1,000 \mathrm{~g})$ decreased significantly during this period, mortality from NEC increased significantly $(0.11 / 1,000$ to $0.17 / 1,000 ; P<0.001)$. This apparent increase in mortality from NEC may be attributable to increasing early survival of extremely low birth weight infants, which increases the number of infants potentially susceptible to NEC.

\section{Current research focus Probiotics}

As previously discussed, it is now well established that abnormal intestinal colonization in preterm infants is associated with an increased incidence of NEC. ${ }^{21,22}$ Probiotics can be defined as living microorganisms that provide health benefits other than nutrition. Probiotics exert their beneficial effect in various ways, such as improving epithelial function, increasing secretory immunoglobulin A, and attenuation of proinflammatory pathways. ${ }^{102}$ Numerous studies have evaluated the use of probiotics to supplement colonization of the preterm gut with commensal flora, and thereby reducing the incidence of NEC. ${ }^{103-107}$ However, there has been wide variation in the timing, dose, and formulation of probiotics used in the various trials. A Cochrane systematic review evaluating the use of probiotics in the prevention of NEC showed a statistically significant reduction in the incidence of NEC and mortality in the probiotics group (NEC RR $0.35,95 \%$ CI $0.24-0.52$ and mortality RR $0.40,95 \%$ CI $0.27-0.60) .{ }^{108}$ Another recent meta-analysis has reported similar results (NEC RR 0.35, 95\% CI 0.23-0.55, $P<0.00001$; mortality RR 0.42, 95\% CI 0.29-0.62, $P<0.00001) .{ }^{109}$ However, the safety and efficacy of use of probiotics have not been fully evaluated, making some clinicians reluctant to start routine supplementation. ${ }^{110}$ Currently in the UK, a multicenter trial has recruited over 1,300 babies to evaluate the effect of a single bacterium (Bifidobacterium breve) on reducing NEC. ${ }^{111}$ Based on the most recent evidence, ${ }^{112}$ some neonatal units have introduced probiotics into routine management of preterm infants.

\section{Lactoferrin}

Lactoferrin is a multifunctional protein found in breast milk and is known to have antimicrobial and anti-inflammatory actions in the human intestine, promoting growth and proliferation of intestinal epithelium and helping in iron absorption. ${ }^{113}$ Animal experiments have shown that lactoferrin when given along with the commensal bacterium Lactobacillus rhamnosus GG (LGG) reduced translocation of bacteria across the intestine. ${ }^{113}$ Manzoni et al ${ }^{114}$ have conducted the only reported randomized controlled trial investigating the efficacy of lactoferrin alone and lactoferrin + LGG in very low birth weight infants in preventing late-onset sepsis and NEC. The incidence of stage 2 and stage 3 NEC was significantly reduced in infants who received lactoferrin + LGG (0/151 infants, $P=0.002)$ compared with infants who received lactoferrin alone (3/153 infants) or the control group (10/168 infants). The incidence of overall late-onset sepsis was also reduced in both the lactoferrin group versus controls and the lactoferrin + LGG group versus controls. Further evidence is awaited before use of lactoferrin becomes part of routine care. A large, UK-based, multicenter, randomized, placebo-controlled trial evaluating the effect of prophylactic lactoferrin on late-onset sepsis, NEC, and other important neonatal morbidities like retinopathy of prematurity and bronchopulmonary dysplasia in very preterm infants, is due to begin recruiting later this year. ${ }^{115}$

\section{Biomarkers}

Researchers have long suspected that a genetic predisposition to NEC might exist, and are focusing on various biomarkers for both predicting infants who are most susceptible to NEC and early identification of NEC. ${ }^{116}$ Genetic markers, such as a specific mannose binding lectin genotype ${ }^{117}$ and variations in the toll-like receptor pathway genes, ${ }^{118}$ may offer a way of predicting preterm infants who are most susceptible to developing NEC. Various other nonspecific biomarkers, including the widely used C-reactive protein, procalcitonin, and some of the "early warning" biomarkers like IL-6 and neutrophil CD64, have been studied to aid in early detection of NEC, but most of these biomarkers are nonspecific and do not differentiate NEC from other infectious/inflammatory conditions. ${ }^{116,119}$

More recently researchers have attempted to identify gutspecific biomarkers such as fatty acid binding protein ${ }^{120}$ and fecal calprotectin ${ }^{121}$ to diagnose NEC early. It is proposed that identification of fatty acid binding protein in the urine of preterm infants during the first few days of life can help in predicting the occurrence of NEC. A research trial will soon 
be recruiting patients in the US to evaluate the effectiveness of urinary fatty acid binding protein monitoring in reducing the incidence of NEC. ${ }^{122}$ Fecal volatile organic compounds (VOCs) are another potential gut-specific biomarker. VOCs are produced due to interaction of bacteria with the intestinal contents. Research has shown that the pattern of VOCs in adult gut disorders such as ulcerative colitis and Clostridium difficile infection is recognizably different compared with healthy subjects. ${ }^{123}$ VOCs can also be measured in preterm infants. ${ }^{124}$ In a pilot study reported in 2009, 58 babies born before 36 weeks' gestation were recruited. ${ }^{125}$ Daily fecal samples were collected and analyzed for VOCs. Six infants developed NEC. After matching the cases to controls according to gestational age and birth weight, there remained a noticeable difference in the pattern of VOCs among infants who developed NEC. These differences were noted up to 4 days before NEC was diagnosed. To explore this further, a large multicenter trial is currently recruiting babies to evaluate the usefulness of VOC detection in early identification of NEC before clinical suspicion arises. ${ }^{126}$

\section{Therapeutic hypothermia for NEC}

Therapeutic hypothermia is a well-established treatment for hypoxic-ischemic brain injury. ${ }^{127}$ The potential for treating NEC in a similar way is currently being explored. In a nonrandomized feasibility trial, Hall et al administered therapeutic hypothermia to 15 infants with advanced NEC and multiorgan dysfunction. ${ }^{128}$ Median gestation at birth of babies in this trial was 27 weeks, with a median admission weight of $1.1 \mathrm{~kg}$. All infants received hypothermia for 48 hours. Five infants were cooled to $35.5^{\circ} \mathrm{C}$, five were cooled to $34.5^{\circ} \mathrm{C}$, and five were cooled to $33.5^{\circ} \mathrm{C}$. The control group comprised ten infants with advanced NEC and multiorgan dysfunction. Hypothermia was maintained within the target range for $90 \%$ of the time. There was no increase in mortality, bleeding, infection, or need for inotropes in the cooled group. Based on this, the CoolNEC (Therapeutic Controlled Hypothermia in the Treatment of Neonates With Severe Necrotizing Enterocolitis) trial is currently recruiting patients with NEC to evaluate the benefit of therapeutic hypothermia in NEC. ${ }^{129}$

\section{Stem cells}

Having recognized the therapeutic role of stem cells in inflammatory bowel conditions like Crohn's disease, their use in NEC has been explored in a well-established rat model of NEC. ${ }^{130}$ Amniotic fluid stem cells injected intraperitoneally resulted in improved survival, decreased the incidence of NEC, and improved the macroscopic appearance and function of the gastrointestinal tract. Use of stem cells in clinical neonatology may not be very close, but is one of the therapeutic options with huge potential, and needs further trials to establish its safety and efficacy.

\section{Summary}

NEC continues to cause significant morbidity and mortality in large numbers of very vulnerable preterm infants. With its multifactorial pathogenesis, disease prevention remains a challenge. Awareness of the risk factors associated with NEC is important. Early initiation of breast milk feeds and a standardized feeding regimen have been shown to reduce the incidence of NEC. Current research is focused on prevention, early diagnosis, and treatment of NEC.

\section{Disclosure}

The authors report no conflicts of interest in this work.

\section{References}

1. Lin PW, Stoll BJ. Necrotizing enterocolitis. Lancet. 2006;368(9543): 1271-1283.

2. Obladen M. Necrotizing enterocolitis -150 years of fruitless search of the cause. Neonatology. 2009;96(4):203-210.

3. Sankaran K, Puckett B, Lee DSC, et al. Variations in incidence of necrotizing enterocolitis in Canadian Neonatal Intensive Care Units. J Pediatr Gastroenterol Nutr. 2004;39(4):366-372.

4. Luig M, Lui K. Epidemiology of necrotizing enterocolitis - Part II: risks and susceptibility of premature infants during the surfactant era: a regional study. J Paediatr Child Health. 2005;41(4):174-179.

5. Guillet R, Stoll BJ, Cotten CM, et al. Association of H2-blocker therapy and higher incidence of necrotizing enterocolitis in very low birth weight infants. Pediatrics. 2006;117(2): e137-e142.

6. Rees CM, Eaton S, Pierro A. National prospective surveillance study of necrotizing enterocolitis in neonatal intensive care units. $J$ Pediatr Surg. 2010;45(7):1391-1397.

7. EXPRESS group. Incidence of and risk factors for neonatal morbidity after active perinatal care: extremely preterm infants study in Sweden (EXPRESS). Acta Paediatr. 2010;99(7):978-992.

8. Yee WH, Soraisham AS, Shah VS, et al. Incidence and timing of presentation of necrotizing enterocolitis in preterm infants. Pediatrics. 2012:129(2):e298-e304.

9. Ahle M, Drott P, Andersson RE. Epidemiology and trends of necrotizing enterocolitis in Sweden: 1987-2009. Pediatrics. 2013;132(2): e443-e451.

10. Wiedmeier SE, Henry E, Baer VL, et al. Center differences in NEC within one health-care system may depend on feeding protocol. $\mathrm{Am} J$ Perinatol. 2008;25(1):5-11.

11. Caplan MS, Simon D, Jilling T. The role of PAF, TLR, and the inflammatory response in neonatal necrotizing enterocolitis. Semin Pediatr Surg. 2005;14(3):145-151.

12. Neu J, Walker WA. Necrotizing enterocolitis. N Engl J Med. 2011; 364(3):255-264.

13. Stoll BJ. Epidemiology of necrotizing enterocolitis. Clin Perinatol. 1994;21(2):205-218.

14. Sharma R, Hudak ML. A clinical perspective of necrotizing enterocolitis: past, present, and future. Clin Perinatol. 2013;40(1):27-51.

15. Salzman NH, Polin RA, Harris MC, et al. Enteric defensin expression in necrotizing enterocolitis. Pediatr Res. 1998;44(1):20-26. 
16. Lin J. Too much short chain fatty acids cause neonatal necrotizing enterocolitis. Med Hypotheses. 2004;62(2):291-293.

17. Reber KM, Nankervis CA, Nowicki PT. Newborn intestinal circulation. Physiology and pathophysiology. Clin Perinatol. 2002;29(1):23-39.

18. Ballance WA, Dahms BB, Shenker N, Kliegman RM. Pathology of neonatal necrotizing enterocolitis: a ten-year experience. $J$ Pediatr. 1990;17(1 Pt 2):S6-S13.

19. Neu J. The 'myth' of asphyxia and hypoxia-ischemia as primary causes of necrotizing enterocolitis. Biol Neonate. 2005;87(2):97-98.

20. McElhinney DB, Hedrick HL, Bush DM, et al. Necrotizing enterocolitis in neonates with congenital heart disease: risk factors and outcomes. Pediatrics. 2000;106(5):1080-1087.

21. Berrington JE, Stewart CJ, Embleton ND, Cummings SP. Gut microbiota in preterm infants: assessment and relevance to health and disease. Arch Dis Child Fetal Neonatal Ed. 2013;98(4):F286-F290.

22. Torrazza RM, Neu J. The altered gut microbiome and necrotizing enterocolitis. Clin Perinatol. 2013;40(1):93-108.

23. Boccia D, Stolfi I, Lana S, Moro ML. Nosocomial necrotizing enterocolitis outbreaks: epidemiology and control measures. Eur J Pediatr. 2001;160(6):385-391.

24. Berseth CL. Feeding strategies and necrotizing enterocolitis. Curr Opin Pediatr. 2005;17(2):170-173.

25. Marchildon MB, Buck BE, Abdenour G. Necrotizing enterocolitis in the unfed infant. J Pediatr Surg. 1982;17(5):620-624.

26. Llanos AR, Moss ME, Pinzon MC, et al. Epidemiology of neonatal necrotizing enterocolitis: a population based study. Paediatr Perinat Epidemiol. 2002;16(4):342-349.

27. Lucas A, Cole TJ. Breast milk and neonatal necrotising enterocolitis. Lancet. 1990;336(8730):1519-1523.

28. Quigley MA, Henderson G, Anthony MY, et al. Formula milk versus donor breast milk for feeding preterm or low birth weight infants. Cochrane Database Syst Rev. 2007;4:CD002971.

29. Sisk PM, Lovelady CA, Dillard RG, et al. Early human milk feeding is associated with a lower risk of necrotizing enterocolitis in very low birth weight infants. J Perinatol. 2007;27(7):428-433.

30. Morgan J, Young L, McGuire W. Delayed introduction of progressive enteral feeds to prevent necrotizing enterocolitis in very low birth weight infants. Cochrane Database Syst Rev. 2013;5:CD001970.

31. Bell MJ. Neonatal necrotizing enterocolitis. N Engl J Med. 1978;298: 281-282.

32. Gordon PV, Swanson JR, Attridge JT, Clark R. Emerging trends in acquired neonatal intestinal disease: is it time to abandon Bell's criteria? J Perinatol. 2007;27(11):661-671.

33. Maheshwari A, Corbin LL, Schelonka RL. Neonatal necrotizing enterocolitis. Res Rep Neonatol. 2011;(1):39-53.

34. Sharma R, Hudak ML, Tepas JJ 3rd, et al. Impact of gestational age on the clinical presentation and surgical outcome of necrotizing enterocolitis. J Perinatol. 2006;26(6):342-347.

35. González-Rivera R, Culverhouse RC, Hamvas A, et al. The age of necrotizing enterocolitis onset: an application of Sartwell's incubation period model. J Perinatol. 2011;31(8):519-523.

36. Piena-Spoel M, Albers MJ, ten Kate J, Tibboel D. Intestinal permeability in newborns with necrotizing enterocolitis and controls: Does the sugar absorption test provide guidelines for the time to (re-)introduce enteral nutrition? J Pediatr Surg. 2001;36(4):587-592.

37. Clark JA, Doelle SM, Halpern MD, et al. Intestinal barrier failure during experimental necrotizing enterocolitis: protective effect of EGF treatment. Am J Physiol Gastrointest Liver Physiol. 2006;291(5):G938-G949.

38. Hackam DJ, Upperman JS, Grishin A, Ford HR. Disordered enterocyte signaling and intestinal barrier dysfunction in the pathogenesis of necrotizing enterocolitis. Semin Pediatr Surg. 2005;14(1):49-57.

39. Puiman PJ, Burger-Van Paassen N, Schaart MW, et al. Paneth cell hyperplasia and metaplasia in necrotizing enterocolitis. Pediatr Res. 2011;69(3):217-223.

40. Coutinho HB, da Mota HC, Coutinho VB, et al. Absence of lysozyme (muramidase) in the intestinal Paneth cells of newborn infants with necrotising enterocolitis. J Clin Pathol. 1998;51(7):512-514.
41. Liu Y, Zhu L, Fatheree NY, et al. Changes in intestinal toll-like receptors and cytokines precede histological injury in a rat model of necrotizing enterocolitis. Am J Physiol Gastrointest Liver Physiol. 2009;297(3): G442-G450.

42. Halpern MD, Clark JA, Saunders TA, et al. Reduction of experimental necrotizing enterocolitis with anti-TNF-alpha. Am J Physiol Gastrointest Liver Physiol. 2006;290(4):G757-G764.

43. Ewer AK, Al-Salti W, Coney AM, et al. The role of platelet activating factor in a neonatal piglet model of necrotising enterocolitis. Gut. 2004;53(2):207-213.

44. De Plaen IG. Inflammatory signaling in necrotizing enterocolitis. Clin Perinatol. 2013;40(1):109-124.

45. Wang Y, Hoenig JD, Malin KJ, et al. 16S rRNA gene-based analysis of fecal microbiota from preterm infants with and without necrotizing enterocolitis. ISME J. 2009;3(8):944-954.

46. Stewart CJ, Nelson A, Scribbins D, et al. Bacterial and fungal viability in the preterm gut: NEC and sepsis. Arch Dis Child Fetal Neonatal Ed. 2013;98(4):F298-F303.

47. Mai V, Young CM, Ukhanova M, et al. Fecal microbiota in premature infants prior to necrotizing enterocolitis. PLoS One. 2011;6(6): e20647.

48. Garite TJ, Clark R, Thorp JA. Intrauterine growth restriction increases morbidity and mortality among premature neonates. Am J Obstet Gynecol. 2004;191(2):481-487.

49. Manogura AC, Turan O, Kush ML, et al. Predictors of necrotizing enterocolitis in preterm growth-restricted neonates. Am J Obstet Gynecol. 2008;198(6):638. e1-e5.

50. Damodaram M, Story L, Kulinskaya E, et al. Early adverse perinatal complications in preterm growth-restricted fetuses. Aust N Z J Obstet Gynaecol. 2011;51(3):204-209.

51. Che L, Thymann T, Bering SB, et al. IUGR does not predispose to necrotizing enterocolitis or compromise postnatal intestinal adaptation in preterm pigs. Pediatr Res. 2010;67(1):54-59.

52. Leaf A, Dorling J, Kempley S, et al. Early or delayed enteral feeding for preterm growth-restricted infants: a randomized trial. Pediatrics. 2012;129(5):e1260-e1268.

53. Dorling J, Kempley S, Leaf A. Feeding growth restricted preterm infants with abnormal antenatal Doppler results. Arch Dis Child Fetal Neonatal Ed. 2005;90(5):F359-F363.

54. Sehgal A, McNamara PJ. The ductus arteriosus: a refined approach! Semin Perinatol. 2012;36(2):105-113.

55. Dollberg S, Lusky A, Reichman B. Patent ductus arteriosus, indomethacin and necrotizing enterocolitis in very low birth weight infants: a population-based study. J Pediatr Gastroenterol Nutr. 2005;40(2): 184-188.

56. Saldeño YP, Favareto V, Mirpuri J. Prolonged persistent patent ductus arteriosus: potential perdurable anomalies in premature infants. $J$ Perinatol. 2012;32(12):953-958.

57. Fowlie PW, Davis PG, McGuire W. Prophylactic intravenous indomethacin for preventing mortality and morbidity in preterm infants. Cochrane Database Syst Rev. 2010;7:CD000174.

58. Ohlsson A, Walia R, Shah SS. Ibuprofen for the treatment of patent ductus arteriosus in preterm and/or low birth weight infants. Cochrane Database Syst Rev. 2013;4:CD003481.

59. Eidelman AI, Schanler RJ, Johnston M, et al. Breastfeeding and the use of human milk. Pediatrics. 2012;129(3):e827-e841.

60. Henderson G, Anthony MY, McGuire W. Formula milk versus maternal breast milk for feeding preterm or low birth weight infants. Cochrane Database Syst Rev. 2007;4:CD002972.

61. Ramani M, Ambalavanan N. Feeding practices and necrotizing enterocolitis. Clin Perinatol. 2013;40(1):1-10.

62. McClure RJ, Newell SJ. Randomised controlled trial of trophic feeding and gut motility. Arch Dis Child Fetal Neonatal Ed. 1999;80(1): F54-F58.

63. McClure RJ, Newell SJ. Randomized controlled study of digestive enzyme activity following trophic feeding. Acta Paediatr. 2002;91(3): 292-296. 
64. Harmsen HJ, Wildeboer-Veloo AC, Raangs GC, et al. Analysis of intestinal flora development in breast-fed and formula-fed infants by using molecular identification and detection methods. $J$ Pediatr Gastroenterol Nutr. 2000;30(1):61-67.

65. Neu J. Gastrointestinal development and meeting the nutritional needs of premature infants. Am J Clin Nutr. 2007;85(2):S629-S634.

66. Lucas A, Bloom SR, Aynsley-Green A. Gut hormones and 'minimal enteral feeding'. Acta Paediatr Scand. 1986;75(5):719-723.

67. Neu J, Douglas-Escobar M, Lopez M. Microbes and the developing gastrointestinal tract. Nutr Clin Pract. 2007;22(2):174-182.

68. Morgan J, Bombell S, McGuire W. Early trophic feeding versus enteral fasting for very preterm or very low birth weight infants. Cochrane Database Syst Rev. 2013;3:CD000504.

69. Morgan J, Young L, McGuire W. Slow advancement of enteral feed volumes to prevent necrotizing enterocolitis in very low birth weight infants. Cochrane Database Syst Rev. 2011;3:CD001241.

70. ClinicalTrials.gov. Speed of increasing milk feeds trial, identifier: NCT01727609. Available from: http://clinicaltrials.gov/show/ NCT01727609. Accessed August 13, 2013.

71. Patole SK, de Klerk N. Impact of standardized feeding regimens on incidence of neonatal necrotizing enterocolitis: a systematic review and meta-analysis of observational studies. Arch Dis Child Fetal Neonatal Ed. 2005;90(2):F147-F151.

72. Cohen RS, McCallie KR. Feeding premature infants: why, when, and what to add to human milk. JPEN J Parenter Enteral Nutr. 2012; 36(Suppl 1):20S-24S.

73. Schanler RJ. Evaluation of the evidence to support current recommendations to meet the needs of premature infants: the role of human milk. Am J Clin Nutr. 2007;85(2):S625-S628.

74. Kuschel CA, Harding JE. Multicomponent fortified human milk for promoting growth in preterm infants. Cochrane Database Syst Rev. 2004;1:CD000343.

75. Sullivan S, Schanler RJ, Kim JH, et al. An exclusively human milkbased diet is associated with a lower rate of necrotizing enterocolitis than a diet of human milk and bovine milk-based products. $J$ Pediatr. 2010;156(4):562-567.

76. Mohamed A, Shah PS. Transfusion associated necrotizing enterocolitis: a meta-analysis of observational data. Pediatrics. 2012;129(3):529-540.

77. Kirpalani H, Whyte RK, Andersen C, et al. The Premature Infants in Need of Transfusion (PINT) study: a randomized, controlled trial of a restrictive (low) versus liberal (high) transfusion threshold for extremely low birth weight infants. J Paediatr. 2006;149(3):301-307.

78. El-Dib M, Narang S, Lee E, et al. Red blood cell transfusion, feeding and necrotizing enterocolitis in preterm infants. J Perinatol. 2011;31(3): 183-187.

79. Christensen RD, Lambert DK, Henry E, et al. Is "transfusion-associated necrotizing enterocolitis" an authentic pathogenic entity? Transfusion. 2010;50(5):1106-1112.

80. La Gamma EF, Blau J. Transfusion-related acute gut injury: feeding, flora, flow and barrier defense. Semin Perinatol. 2012;36(4):294-305.

81. Shah P, Nathan E, Doherty D, Patole S. Prolonged exposure to antibiotics and its associations in extremely preterm neonates - the Western Australian experience. J Matern Fetal Neonatal Med. May 13, 2013. [Epub ahead of print.]

82. Cotten CM, Taylor S, Stoll B, et al. Prolonged duration of initial empirical antibiotic treatment is associated with increased rates of necrotizing enterocolitis and death for extremely low birth weight infants. Pediatrics. 2009;123(1):58-66.

83. Bose CL, Laughon MW. Patent ductus arteriosus: lack of evidence for common treatments. Arch Dis Child Fetal Neonatal Ed. 2007;92(6): F498-F502.

84. Rand T, Weninger M, Kohlhauser C, et al. Effects of umbilical arterial catheterization on mesenteric hemodynamics. Pediatr Radiol. 1996;26(7):435-438.

85. Barrington KJ. Umbilical artery catheters in the newborn: effects of position of the catheter tip. Cochrane Database Syst Rev. 1999;1: CD000505.
86. Gantert M, Been JV, Gavilanes AW, Garnier Y, Zimmermann LJ, Kramer BW. Chorioamnionitis: a multiorgan disease of the fetus? J Perinatol. 2010;30 Suppl:S21-S30.

87. Lau J, Magee F, Qiu Z, et al. Chorioamnionitis with a fetal inflammatory response is associated with higher neonatal mortality, morbidity and resource use than chorioamnionitis displaying a maternal inflammatory response only. Am J Obstet Gynecol. 2005;193(3 Pt 1):708-713.

88. Thompson A, Bizzarro M, Yu S, Diefenbach K, Simpson BJ, Moss RL. Risk factors for necrotizing enterocolitis totalis: a case-control study. $J$ Perinatol. 2011;31(11):730-738.

89. Yee WH, Soraisham AS, Shah VS, Aziz K, Yoon W, Lee SK. Incidence and timing of presentation of necrotizing enterocolitis in preterm infants. Pediatrics. 2012;129(2):e298-e304.

90. Aziz N, Cheng YW, Caughey AB. Neonatal outcomes in the setting of preterm premature rupture of membranes complicated by chorioamnionitis. J Matern Fetal Neonatal Med. 2009;22(9): 780-784.

91. Andrews WW, Goldenberg RL, Faye-Petersen O, Cliver S, Goepfert AR, Hauth JC. The Alabama Preterm Birth study: polymorphonuclear and mononuclear cell placental infiltrations, other markers of inflammation, and outcomes in 23- to 32-week preterm newborn infants. Am J Obstet Gynecol. 2006;195(3):803-808.

92. Been JV, Lievense S, Zimmermann LJ, et al. Chorioamnionitis as a risk factor for necrotizing enterocolitis: a systematic review and meta-analysis. J Pediatr. 2013;162(2):236-242.

93. Giannone PJ, Nankervis CA, Richter JM, Schanbacher BL, Reber KM. Prenatal lipopolysaccharide increases postnatal intestinal injury in a rat model of necrotizing enterocolitis. J Pediatr Gastroenterol Nutr. 2009;48(3):276-282.

94. Pierro A. The surgical management of necrotizing enterocolitis. Early Hum Dev. 2005;81(1):79-85.

95. Kastenberg ZJ, Sylvester KG. The surgical management of necrotizing enterocolitis. Clin Perinatol. 2013;40(1):135-148.

96. Tepas JJ 3rd, Sharma R, Leaphart CL, et al. Timing of surgical intervention in necrotizing enterocolitis can be determined by trajectory of metabolic derangement. J Pediatr Surg. 2010;45(2):310-313.

97. Rao SC, Basani L, Simmer K, Samnakay N, Deshpande G. Peritoneal drainage versus laparotomy as initial surgical treatment for perforated necrotizing enterocolitis or spontaneous intestinal perforation in preterm low birth weight infants. Cochrane Database Syst Rev. 2011;6: CD006182.

98. Blakely ML, Tyson JE, Lally KP, et al. Laparotomy versus peritoneal drainage for necrotizing enterocolitis or isolated intestinal perforation in extremely low birth weight infants: outcomes through 18 months adjusted age. Pediatrics. 2006;117(4):e680-e687.

99. ClinicalTrials.gov. Laparotomy vs drainage for infants with necrotizing enterocolitis (NEST) trial. Clinicaltrials.gov Identifier: NCT01029353. Available from: http://clinicaltrials.gov/ct2/show/ NCT01029353?term=NEST\&rank=2. Accessed November 11, 2013.

100. Blakely ML, Lally KP, McDonald S, et al. Postoperative outcomes of extremely low birth-weight infants with necrotizing enterocolitis or isolated intestinal perforation: a prospective cohort study by the NICHD Neonatal Research Network. Ann Surg. 2005;241(6):984-989.

101. Rees CM, Eaton S, Pierro A. Trends in infant mortality from necrotising enterocolitis in England and Wales and the USA. Arch Dis Child Fetal Neonatal Ed. 2008;93(5):F395-F396.

102. Patel RM, Denning PW. Therapeutic use of prebiotics, probiotics, and postbiotics to prevent necrotizing enterocolitis: what is the current evidence? Clin Perinatol. 2013;40(1):11-25.

103. Dani C, Biadaioli R, Bertini G, et al. Probiotics feeding in prevention of urinary tract infection, bacterial sepsis and necrotizing enterocolitis in preterm infants. A prospective double-blind study. Biol Neonate. 2002;82(2):103-108.

104. Manzoni P, Mostert M, Leonessa ML, et al. Oral supplementation with Lactobacillus casei subspecies rhamnosus prevents enteric colonization by Candida species in preterm neonates: a randomized study. Clin Infect Dis. 2006;42(12):1735-1742. 
105. Mohan R, Koebnick C, Schildt J, et al. Effects of Bifidobacterium lactis Bb12 supplementation on intestinal microbiota of preterm infants: a double-blind, placebo-controlled, randomized study. J Clin Microbiol. 2006;44(11):4025-4031.

106. Stratiki Z, Costalos C, Sevastiadou S, et al. The effect of a bifidobacter supplemented bovine milk on intestinal permeability of preterm infants. Early Hum Dev. 2007;83(9):575-579.

107. Fernandez-Carrocera LA, Solis-Herrera A, Cabanillas-Ayon M, et al. Double-blind randomised clinical assay to evaluate the efficacy of probiotics in preterm newborns weighing less than $1500 \mathrm{~g}$ in the prevention of necrotising enterocolitis. Arch Dis Child Fetal Neonatal Ed. 2013;98(1):F5-F9.

108. Alfaleh K, Anabrees J, Bassler D, Al-Kharfi T. Probiotics for prevention of necrotizing enterocolitis in preterm infants. Cochrane Database Syst Rev. 2011;3:CD005496.

109. Deshpande G, Rao S, Patole S, Bulsara M. Updated meta-analysis of probiotics for preventing necrotizing enterocolitis in preterm neonates. Pediatrics. 2010;125(5):921-930.

110. Agostoni C, Buonocore G, Carnielli VP, et al. Enteral nutrient supply for preterm infants: commentary from the European Society of Paediatric Gastroenterology, Hepatology and Nutrition Committee on Nutrition. J Pediatr Gastroenterol Nutr. 2010;50(1):85-91.

111. United Kingdom National Perinatal Epidemiology Unit. Probiotics in Preterm babies Study (PiPS). Available from: https://www.npeu. ox.ac.uk/pips. Accessed August 14, 2013.

112. Bernardo WM, Aires FT, Carneiro RM, Sá FP, Rullo VE, Burns DA. Effectiveness of probiotics in the prophylaxis of necrotizing enterocolitis in preterm neonates: a systematic review and meta-analysis. J Pediatr (Rio J). 2013;89(1):18-24

113. Sherman MP. Lactoferrin and necrotizing enterocolitis. Clin Perinatol. 2013;40(1):79-91.

114. Manzoni P, Rinaldi M, Cattani S, et al. Bovine lactoferrin supplementation for prevention of late-onset sepsis in very low-birth-weight neonates: a randomized trial. JAMA. 2009;302(13):1421-1428.

115. United Kingdom National Perinatal Epidemiology Unit. Prophylactic enteral lactoferrin supplementation to prevent late-onset invasive infection in very preterm infants (ELFIN) trial. Available from: https:// www.npeu.ox.ac.uk/elfin. Accessed September 23, 2013.

116. Ng PC, Chan KY, Poon TC. Biomarkers for prediction and diagnosis of necrotizing enterocolitis. Clin Perinatol. 2013;40(1):149-159.

117. Prencipe G, Azzari C, Moriondo M, et al. Association between mannose-binding lectin gene polymorphisms and necrotizing enterocolitis in preterm infants. J Pediatr Gastroenterol Nutr. 2012;55(2): $160-165$

118. Sampath V, Le M, Lane L, et al. The NFKB1 (g.-24519delATTG) variant is associated with necrotizing enterocolitis (NEC) in premature infants. J Surg Res. 2011;169(1):e51-e57.
119. Ng PC, Lam HS. Biomarkers in neonatology: the next generation of test. Neonatology. 2012;102(2):145-151.

120. Aydemir C, Dilli D, Oguz SS, et al. Serum intestinal fatty acid binding protein level for early diagnosis and prediction of severity of necrotizing enterocolitis. Early Hum Dev. 2011;87(10):659-661.

121. Thuijls G, Derikx JP, van Wijck K, et al. Non-invasive markers for early diagnosis and determination of the severity of necrotizing enterocolitis. Ann Surg. 2010;251(6):1174-1180.

122. ClinicalTrials.gov. Prediction of NEC with Urinary iFABP trial. Clinicaltrials.gov identifier: NCT01805206. Available from: http:// clinicaltrials.gov/ct2/show/NCT01805206?term=necrotizing+enteroco litis\&recr=Open\&no_unk=Y\&cntry1=NA\%3AUS\&rank=3. Accessed November 11, 2013.

123. Garner CE, Smith S, Ratcliffe NM, et al. Volatile organic compounds from feces and their potential for gastrointestinal disease diagnoses. FASEB J. 2007;21(8):1675-1688.

124. De Lacy Costello B, Ewen R, Ewer AK, et al. An analysis of volatiles in the headspace of the faeces of neonates. $J$ Breath Res. 2008;2(3):037023.

125. Garner CE, Ewer AK, Elasouad K, et al. Analysis of fecal volatile organic compounds in preterm infants who develop necrotizing enterocolitis: a pilot study. J Pediatr Gastroenterol Nutr. 2009;49(5): 559-565.

126. United Kingdom Clinical Research Network. The DOVE study. Available from: http://england.ukcrn.org.uk/StudyDetail. aspx?StudyID=10843. Accessed August 14, 2013.

127. Higgins RD, Raju T, Edwards AD, et al. Hypothermia and other treatment options for neonatal encephalopathy: an executive summary of the Eunice Kennedy Shriver NICHD workshop. J Pediatr. 2011; 159(5):851-858.

128. Hall NJ, Eaton S, Peters MJ, et al. Mild controlled hypothermia in preterm neonates with advanced necrotizing enterocolitis. Pediatrics. 2010;125(2):e300-e308.

129. ClinicalTrials.gov. Therapeutic Controlled Hypothermia in the Treatment of Neonates With Severe Necrotizing Enterocolitis (CoolNEC) trial. Available from: http://clinicaltrials.gov/show/NCT01330576. Accessed August 14, 2013.

130. Zani A, Cananzi M, Fascetti-Leon F, et al. Amniotic fluid stem cells improve survival and enhance repair of damaged intestine in necrotising enterocolitis via a COX-2 dependent mechanism. Gut. March 24, 2013. [Epub ahead of print.]

131. Walsh MC, Kliegman RM. Necrotizing enterocolitis: treatment based on staging criteria. Pediatr Clin North Am. 1986;33(1):179-201.
Research and Reports in Neonatology

\section{Publish your work in this journal}

Research and Reports in Neonatology is an international, peer-reviewed, open access journal publishing original research, reports, editorials, reviews and commentaries on neonatal health. The manuscript management system is completely online and includes a very quick and fair

\section{Dovepress}

peer-review system. Visit http://www.dovepress.com/testimonials.php to read real quotes from published authors. 